\title{
Research on Welding Repair Process for Large-scale Cast Steel Parts of Marine Diesel Engine
}

\author{
Zhao Zhiqiang ${ }^{1}$, Guo Haijian² \\ ${ }^{1}$ Binzhou Polytechnic, Binzhou, Shandong, China, 256600 \\ ${ }^{2}$ Qilu Traffic Development Group co., Ltd. Binzhou Branch, Binzhou, Shandong, China, 256600
}

Keywords: welding repair process; large-scale cast steel; residual stress

\begin{abstract}
Marine cast steel parts generally have features such as large cross-section dimensions and complex shapes, hard to repair once damaged. This paper analyzes the cracks and causes of weld cracks commonly found in the welding of large steel castings, takes the repair of diesel cylinders as an example, and analyzes the common welding repair methods for steel castings. The welding repair through the cylinder shows that under the strict control of the welding process, the heterogeneous cold welding repair process is practically applicable to the on-site repair. And cracks may occur in the nickel-based welds after the diesel engine actually operates. The welding repair process should be strictly controlled and appropriate measures should be taken to eliminate the welding residual stress.
\end{abstract}

\section{Introduction}

The steel castings in the marine diesel engine structure generally have large thickness and rigidity, and the shape is complex [1]. They are often used in structural parts that are subject to heavy loads, and most of them are used under high temperature and high pressure conditions, and their working conditions are harsh, which requires high safety level. The cylinder not only bears the working stress of high temperature and high pressure steam under the condition of engine starting, stopping and peak regulating, but also bears the thermal stress, such as the change of steam temperature, the internal and external wall, the temperature difference between the upper and lower cylinders. In addition, due to factors such as large volume and different cooling rates in the manufacturing process, large variation in wall thickness at different locations, other components such as the main cylinder and regulating cylinder often have different structure inhomogeneity, and often accompanied by the existence of casting defects. The cracking of large steel castings will seriously affect the safe operation of the diesel engine.

\section{Types and Causes of Welding Cracks}

\subsection{Type of crack}

Table1. Types of cold cracks

\begin{tabular}{cl}
\hline Types & \multicolumn{1}{c}{ Features } \\
\hline Weld toe crack & $\begin{array}{l}\text { Originated in the junction of the base metal and the weld, and there are } \\
\text { obvious stress concentration sites. The cracks are often parallel to the weld } \\
\text { bead. Generally, the weld toe surface begins to expand deeper into the base } \\
\text { metal. } \\
\text { Often occurs in the welding heat affected zone with high hardened } \\
\text { tendency and high hydrogen content. In general, the crack trend is parallel } \\
\text { to the fusion line. } \\
\text { It mainly occurs in the case of high hydrogen content and insufficient } \\
\text { preheating temperature. It originates from the site where the stress } \\
\text { concentration at the root of the weld is the largest. }\end{array}$ \\
\hline
\end{tabular}


Cracks are the most serious flaw in welded joints of large steel castings, which are extremely harmful. Cracks in welding joints are not only produced by welding cracks in the welding process, but also in the post weld heat treatment, such as the cracks produced during the treatment of stress treatment, which is produced when the welding joint is reheated to high temperature, and can be called reheat crack [2]. Another kind of crack is to appear only after a period of time. It is a small number of cracks appear to gradually increase and expand with time, which is called delayed crack. Some of the most common types of cold cracks that are easily generated during the most critical welding process for casting butt joints are showed in table 1.

\subsection{Cause of cold crack formation}

The influence of the chemical composition of the cast steel on the formation of cold cracks. The hardening tendency of the cast steel depends largely on the chemical composition of the cast steel. When the steel has a large hardening tendency, the flake martensite will appear under the rapid cooling, and the twin martensite, also known as twin martensite, is found in the sheet.

The effect of hydrogen and carbon on the formation of cold cracks. Cold cracking occurs in the rich hydrogen zone. It can be seen that hydrogen has a very important influence on cold cracking. At this point, hydrogen escapes vigorously, but because of the rapid cooling rate, hydrogen can not escape and remains in the weld metal, which makes the hydrogen supersaturated. When the concentration of hydrogen is high enough, cracks on the root or toe of weld will occur. In general, the hydrogen content of the cast steel is very low, and the selected welding material is also low hydrogen type. However, because of the external factors such as transportation, storage and pretreatment, the hydrogen is enriched, such as the moisture in the welding material, the rust, oil pollution and the ambient humidity at the groove of the welding parts are all the reasons for the hydrogen rich in the weld. In addition, the groove and the clear root are often made of carbon arc gouging. The carbon traces at the groove must be polished and whited to reduce the carbon equivalent of the weld. Therefore, the control of the welding environment, such as the drying of the welding rod, the cleaning of the groove must be strict. This point is especially important for the welding of large steel castings that are operated almost completely in the open air.

The influence of welding process on the formation of cold cracks: For the main welding structures, the control of welding line energy is particularly strict. The overheating of the line energy will cause the overheating of the heat affected zone to make the grain large and reduce the crack resistance of the joint, while the low line energy will reduce the cooling time, make the heat affected zone harden, and not benefit the escape of hydrogen, and increase the cold cracking tendency. Therefore, when welding process is formulated, the welding line energy should be selected reasonably and strictly controlled during construction, so that it is not allowed to arbitrarily changed.

\section{Welding Repair Process Analyses}

\subsection{Clearance of defects and damages}

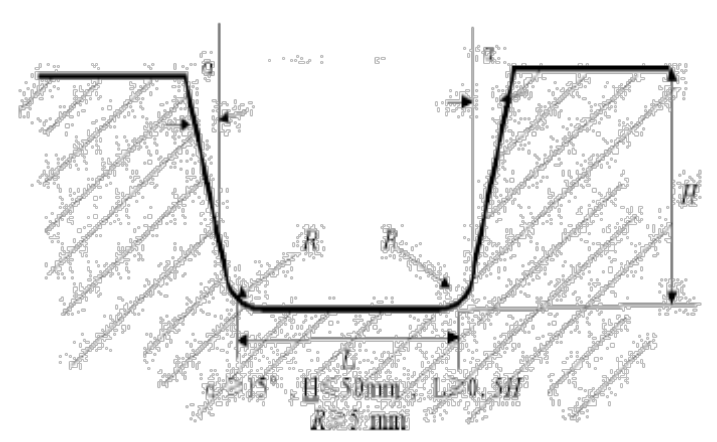

Fig.1 Sketch map of welding groove

First, mechanical methods, as grinding with angle grinders, are used to remove metal and cracks 
from the mechanical damage parts, and observe while grinding. Permeation testing is used to check cracks until all cracks are eliminated. The extruded parts were polished smooth, and the existing cracks were completely removed. Finally, penetrant inspection was used to confirm the complete removal of cracks. The sloping U-shaped groove is used for the grinding groove, so that the amount of filling metal can be reduced. Both ends of the groove are also ground into a smooth transition. The groove size is shown in Figure 1.

\subsection{Welding repair process}

Due to the irregular shape of the repaired area, manual welding was selected. The electrode arc welding method has the advantages of being flexible, convenient and fast in the field repair, so the electrode arc welding process is selected. The following are the steps to be taken in the welding process. Welding method: electrode arc welding. Welding characteristics is heterogeneous cold welding process. Welding consumables is Nickel-based welding consumables. The electrode was dried at $360{ }^{\circ} \mathrm{C}$ per two hours, placed in a welding rod insulation tube, and turned on with electricity. Clean grease, rust, and other dirt on the surface of clean wire. Clean the groove and the area in the vicinity of $18 \mathrm{~mm}$ with clean alcohol or acetone, and use the penetrant inspection to detect defects such as cracks in the groove and its vicinity within $18 \mathrm{~mm}$. Flame preheating, the temperature in the range of $140 \mathrm{~mm}$ around the groove must reach $200-210^{\circ} \mathrm{C}$, and it should be packed with heat-insulating material such as asbestos. Under the condition of ensuring good fusion, a small welding current is used to reduce the dilution of base metal with a $2.2 \mathrm{mmENiCrFe}-3$ welding rod. Continuous welding is used during welding. After welding, the half of the welding seam is first welded. The bottom layer should cover all the groove faces.

After the welding of the bottom layer is completed, the insulation is slowly cooled with asbestos, and the macroscopic inspection is performed after the temperature is reached to room temperature. The welding soldering layer is preheated again according to the above steps, and welding is continued until it is qualified. When the room temperature is lower than $0{ }^{\circ} \mathrm{C}$ during welding, the second layer is heated to $40{ }^{\circ} \mathrm{C}$ before welding, and then welded throughout the welding process. When the arc is closed, the arc pit is filled and hammering is performed immediately after welding. Hammer should be hammered first in the middle of the weld bead and then hammered on both sides of the bead. Hammer marks should be compact and tidy to avoid repetition.

After cooling to room temperature, rough grinding is performed using an angle grinder, and the weld bead is ground to make it closely resemble the surrounding shape, leaving fine grinding and polishing allowance. After the welding is completed, the weld metal is refined, rough ground and polished. Penetration testing was performed after the welding was cooled and after $24 \mathrm{~h}$. No linear defect indications were found and the welds passed the NDT test. According to the requirements, the hardness of the weld and the base metal meet the requirements and the hardness is well matched.

\section{Assessment of the Welding Repair}

\subsection{Nondestructive examination}

The penetrant inspection of the repaired area of another cylinder of the diesel engine was carried out. It was found that there was a crack in the original repaired area. No traces such as cracks were found in other areas. Grind the repaired area where the crack is present, and then polish the polished area to a smooth transition. The cylinder was repaired using the same repair process as last time. The cold welding repair process using ENiCrFe-3 welding rods. In order to ensure the safe operation of the unit, safety assessment should be conducted after the cylinder is rewelded and repaired again.

\subsection{Safety assessment}

The cracks found during this non-destructive testing process are located on the edge of the original nickel-base repair zone and extend to the parent material. And after grinding about $28 \mathrm{~mm}$ deep cracks are all eliminated. This shows that the welding residual stress in the original welding area is 
large, and there is no better way to deal with the stress under the site conditions. The repair welding area is located at the shoulder of the cylinder body and is at the variable cross section, which is the stress concentration area. Therefore, nickel-based repair welding seams and its vicinity are prone to cracking [3]. If the cylinder is repaired in the same position again, the residual stress in the repair welding area will be increased again, and it is difficult to ensure that cracks will not be generated again. This will have potential hidden troubles and adverse effects on the safe operation of the unit. In addition, the microstructure of the cylinder is not uniform in microstructure, which causes the inhomogeneous properties of the material; early cracking is easy to occur in the area with uneven tissue and performance. According to the comprehensive analysis, the cylinder should be replaced as soon as possible during the next shutdown or overhaul.

\section{Summary}

Through the analysis of the welding repair of the above two components, the welding repair characteristics of the large steel castings of the marine diesel engine can be obtained, that is, the creep resistant heat-resistant Cr-Mo-V alloy steel is mostly used for casting; And due to the start and stop of the unit and the change of the working medium temperature, the steel castings are also subjected to thermal stress caused by the temperature difference between the inner and outer walls of the unit and the temperature difference and non-uniformity of the different parts. Under the starting and stopping conditions of the diesel engine, there is a thermal stress caused by the difference in the thermal expansion coefficient between the nickel-base weld metal and the base metal, which leads to the failure of the nickel-based repair weld in the long-term operation. Therefore, it should control the welding repair process strictly, take appropriate measures to eliminate the welding residual stress, such as vibration aging, ultrasonic stress relief measures, can greatly improve the repair of welded joints anti-fatigue cracking ability.

\section{References}

[1] Xue Digan. Introduction to welding[M]. Beijing: Mechanical Industry Press. 2012, p.106

[2] Cui Zhongxin. Metallography and Heat Treatment[M]. Harbin: Harbin Institute of Technology. 2005, p.23

[3] Song Dongyang. Feasibility of Elimination of Welding Stress by Vibration Aging[J]. Water Conservancy \& Electric Power Machinery, 2015,27 (3), p.41 